\title{
Social process tracing - bringing back the social into the process
}

\author{
Authors: \\ Mathilde Cecchini (mcecchini@ps.au.dk) \\ Jonas Gejl Kaas (gejl@ps.au.dk) \\ DerekBeach (derek@ps.au.dk)
}

Department of Political Science

Aarhus University, Denmark

Work in progress -first draft

[Due to suboptimal work conditions during the COVID-19 pandemic, this paper is far from a finished draft. We do however look forward to comments and suggestions] 


\section{Introduction}

Process tracing methods are increasingly popular in the social sciences. At the same time, most existing guidelines miss 'the social' when studying political and social processes. In effect, existing guidelines for PT suggest there is little difference between studying the natural world and the social world.

At the theoretical level, the goal of process tracing is to uncover the intermediate steps of a process linking causes and outcomes together (Bennett and Checkel, 2014), which can be done by theorizing the entities involved and the activities that they engage in that provide the causal linkages in the process (Beach and Pedersen, 2019). However, what is missing in these accounts is that the activities of entities as social actors take place in a context of social resources and relations (for an exception, see next section). For example, the activity of a policy entrepreneur tabling a proposal might only 'work' in a context in which the entrepreneur is trusted by other actors because of strong social ties.

At the empirical level, in some of the literature there is a focus on 'diagnostic evidence' (Bennett and Checkel, 2014), or 'causal process observations' (Collier, Brady and Seawright, 2010), but in the rush to distinguish process tracing evidence from cross-case evidence of the difference that variation of a cause makes on values of the outcome (aka data-set observations), little guidance is provided for what process tracing evidence looks like. Beach and Pedersen (2019) go somewhat further, drawing on the literature on 'mechanistic evidence' from the natural sciences (Russo and Williamson, 2007; Illari, 2011) to define process tracing evidence as the observable traces left by the activities of entities (Beach and Pedersen, 2019: 4-6, 55-6). However, this focus on the 'observable traces' can be understood as 'experience-distant' evidence, where the researcher imposes outside categories onto the social process as experienced by participants, thereby missing the dimension of action (see Geertz 1974: 28-29; Schaffer 2012). In effect, this means that an important perspective for gathering evidence is often discounted in process tracing case studies. 
In this article, we attempt to reconstruct process tracing methodology to create what we term 'social process tracing' methods, making it better suited to studying social processes, enabling the theorization of more socially-contextualized processes, and empirical analysis that supplements existing forms of process tracing evidence with 'experience-near' evidence based on participant understandings of specific settings and actors in question. In other words, to incorporate the beliefs, values and meanings of individuals to the causal explanation.

In order to do this, at the theoretical level we revisit the realist philosophical foundations of process tracing methods by drawing on the work of scholars such as Abbott (1995), Archer (1995) and Sayer (2000), but also more interpretivist scholars like Emirbayer (1997) and Sewell (1992) to develop a language for how the ability of actors to engage in activities is shaped by the interplay between a material and social dimension of the context within which they are embedded. Even further, scholars in these fields contend that actors are not even fixed entities during processes, but instead can be shaped by the very social processes they are involved in, resulting in changes in actor interests and identities. At the empirical level, we draw on ideas from mainstream interpretivist methodologies and how they attempt to tap into 'the social' empirically in order to provide a supplemental perspective on how a social process played out in a realworld case (e.g., Yanow \& Schwartz-Shea 2012 \& 2014; Schaffer, 2016; Fujii, 2018). Note that this goes beyond merely asking participants about their perceptions of what events took place, or whether they trusted actor B in a given situation which is sometimes done in traditional process tracing, but often taking the researchers context (experience-distant concepts) as a point of departure. Instead this approach is an attempt to situate and understand the meanings that participants give to actions in context(Malinowski 1922, Geertz 1974, Geertz 1993; Fujii, 2018). By doing so, this approach seeks bridge the experience-near meanings of participants with experience-distant concepts of the researcher. These ideas are not antithetical to realist philosophy, and it is important to note that the social process tracing methodology that we develop is not a more 'reflectivist' position of 'social' all the way down. Instead, we suggest a middle-ground in which interpretations are but one set of empirical insights that can be used by the analyst to understand how a social process played out, enabling evidence-based process theories to be developed that capture both the physical and social dimensions of action. 
The paper proceeds in three steps. First, we unpack the ontological and epistemological foundations of existing process tracing methods in order to reconstruct a social process tracing methodology that builds on insights from realist philosophy and interpretivism. At the ontological level, process tracing builds on a processual, or mechanistic understanding of causation, but where the social contextual dimension of action is often neglected. The focus on social context is a comparative strength of realist philosophy as it has been applied to the social sciences (Sayer, 2000; Maxwell, 2012; Danemark et al, 2019), but these ideas are relatively vague and require further development before they can be applied to practical theorization of social processes - the development of which is one contribution of this article. Many interpretivists share an interest in process, but often refrain from using "causal language" that is talking about a cause and an outcome, although some form of causality is implied when interpretivist scholars talk about "construction", "formation", "transformation" etc. In addition to providing researchers doing process tracing with a framework for incorporating the social dimension of a causal process, the paper may also provide inspiration for scholars doing interpretivist research on how to examine processes and causal linkages in ways that can be understood by more positivistic case study researchers.

At the epistemological level, we draw on ideas from interpretivism about how to explore empirically how social actors make sense of their social setting (Schwarz-Shea and Yanow, 2014; Bevir and Blakely, 2018; Fujii, 2018). Building on hermeneutic and phenomenological foundations interpretivists believe that tapping into how social actors perceive the social dimension is vital, for example the impact that a particular speech acts depends on how actors make sense of it in the social context. We attempt to build a pragmatic, epistemological middleground that uses both experience-distant and experience-near evidence from social processes playing out, thereby also diverging from more 'reflectivist' versions of interpretivism in which there is no independence of referents from signification practices (see Bourdieu and Wacquant, 1996; Yanow and Schwartz-Shea, 2012, 2014). For more reflectivist variants of interpretivism, it is counterproductive to attempt to disentangle the social from the material (see also Jackson 2016; Bevir and Blakely, 2018), whereas what we intend is to encourage a dialogue between the different forms of empirical material in order to shed more light on both the physical and social dimensions of causal processes. 
Second, building on these ontological and epistemological foundations, we then unpack in more practical terms how social process tracing can be deployed through abductive research practices that move back-and-forth between the empirical and theoretical levels to generate analytical abstractions about how social processes unfolded in particular social contexts. We develop guidelines for the key steps of social process tracing, including: 1) initial theorization using more experience-distant theoretical ideas, 2) empirical probing to explore social context and assess experience-near understandings of the process and what it is a 'case of', along with assessment of the positionality of the researcher, and engaging in juxtaposition of theoretical and empirical ideas that attempts to 'bridge' the experience-near and distant to understand how a social process plays out at the level of intersubjective experiences of agents.

\section{The ontological and epistemological foundations of social process tracing}

In this section, we first discuss the neglect of the 'social' in many existing accounts of process tracing. We then explore the commonalities (and differences) in the fundamental ontological and epistemological foundations of both critical realism and interpretivist positions in order to flesh out the commonalities upon which we can develop a social process tracing methodology.

\section{2a. Existing process tracing accounts downplay the 'social'}

While process tracing builds on realist philosophical foundations, focusing on how causal processes (aka mechanisms) play out by tracing their observable manifestations empirically within cases (George and Bennett, 1995: 135-6; Beach and Pedersen, 2019). However, most existing accounts of the method have forgotten the social dimension of processes that plays such an important role in the work of authors such as Sayer (2000), Archer (1995), Sewell (1996), Somers and Block (2005), and others. Pouliot (2014) does put forward some ideas of a more interpretivist variant of process tracing that he termed 'practice tracing', but as he then weds the approach to a Bourdieu's practice theory, it becomes a narrow approach that can be used within a particular theoretical framework. We intend to develop an approach that can work within a multitude of different theoretical frameworks. 


\section{2.b. A shared ontology of process and social context}

Realism as a philosophical approach was originally framed as a broad theory of science (e.g. Bhaskar, 1979), whereas the core tenets of interpretivism were explicitly developed to distinguish the study of the social from the natural sciences. Later work has adapted realism to the social sciences (e.g. Sayer, 2000; Maxwell, 2012; Danermark et al, 2019), developing many commonalities with interpretivism; in particular the focus on process and the relational and contextual nature of social action.

At its core, realist approaches distinguish between three levels of reality: 1) the real, which are the fundamental structures and capacities that flow from it that undergird social reality; 2) the actual, which involves the actuation of processes and activities of social actors with capacities do things in particular social and material contexts; and 3) the empirical, which is the realism of observables left by the actual processes playing out in particular case contexts. In this threefold ontology, we can see the clear focus on processes, as well as the importance of context that stems from the 'real' that shape the context within which action can take place in the 'actual'. Processes can be quite fluid, in which social actors and their capacities can change during process, mapping nicely onto ideas from sociologists like Abbott (1988), Archer (1995) and Tilly (1995). For example, a state that goes to war becomes transformed by the activities of warfare, resulting in a very different 'state' coming out of the process than went in.

In a similar vein, interpretivists are generally interested in understanding the processes about how individual and collective identities, interests, and capacities for action are reconstructed via encounters between individual and collective actors in specific settings. For instance, Patrick T. Jackson (2006) demonstrates the process of rhetorically constructing the commonplace "Western Civilization" in postwar West Germany was essential to the reconstruction of its Cold War foreign policy and role within the postwar world order.

Given realists' and interpretivists' shared interest in process, this brings the activities of social actors to the foreground, although the terminology used by the two approaches is often quite different. In a realist perspective, activities of social actors are enabled by their context, and activities are the critical causal linkages in processes. Interpretivists typically are less interested in causal linkages, but instead in understanding what particular acts mean in a given 
social context, focusing for instance on speech acts or sets of practices of social actors, and the role they play in reconstructing social reality and rendering certain actions meaningful and others meaningless.

Another key commonality is that how processes play out are not pre-determined, but instead are shaped by the context in which they occur. For both approaches, context means more than just the material resources available to actors, for example due to possessing privileged institutional positions. Instead, the social context of action also matters. For example, the ability of one actor to persuade another actor through speech acts can be dependent on the degree to which the actor trusts the other actor that is a function of their social relationship. A focus on the social context of action means that social relations between actors are important to understand how processes work.

Note that there is nothing inherent in these core ontological principles underlying social process tracing that dictate that particular theoretical frameworks like Bourdieu's practice theory or Giddens' structuration theory have to be utilized by the analyst. In principle, a coherent research methodology should be compatible with many different theoretical frameworks, as long as the theories being operated are interested in the processual dimension of causation, and the theory's foundational ontological assumptions about the world do not clash with an interest in the social dimension - which may be the case with more rational choice-oriented frameworks. This also means that purely structural theories in which there is no 'action' are not suitable for analyzing with social process tracing, although even here social process tracing can be used if a structural analysis is translated into more processual terms for example by theorizing how a stable equilibrium is sustained through the actions of individuals and institutions.

Additionally, when we speak of processes, there is nothing inherent in either critical realism or interpretivism that states that social actors have to be at the micro-level. Social actors in both approaches can be both micro-level individuals and macro-level actors such as states or other collective actors in which there is 'emergence', where the collective properties of actor that are not reducible to the sum of the individuals. 


\section{2.c. Epistemology and studying the social}

At the epistemological level, realism and interpretivism share the belief that tapping into how social actors perceive the social dimension is a vital source of information for the analyst. For example both would agree that the significance of particular speech acts depends on the relational context in which they take place, which can only be understood by also probing how the actors themselves understood the speech acts. Where some more reflectivist versions of interpretivism would part company with realists is regarding whether there is some independence of referents from signification practices. Reflectivists argue for mind-world monism in which researcher and the actors and settings being researched are part of the same world (Jackson 2016). Unlike the dualism of realism, no world exists independent of the social-nor natural-and no meaningful separation can be made between the world of the researcher and world being researched to reflectivists (e.g. Bevir and Blakely, 2018).

For realists, actors are viewed as having intentions when acting, which means that to study activities empirically we need to attempt to understand what actors mean when they say something, and the effect these actions have on other social actors by relating their discourse to its referents and social context (Sayer, 2000: 20). However, understanding the social dimension of action is not the only analytical tool that would be used by the realist. Instead, more 'objective', experience-distant empirical observation of traces left by activities. In other words, the material/physical dimension of action is also important to study empirically.

For interpretivists, actors' actions are situated in social settings consisting of web of meanings. To explain action, interpretivists need-like critical realists-to understand what action meant to specific actors (Fujii, 2018: 74). In order to understand actors, interpretivists need to access, explore and even embed themselves in these situated web of meanings. Interpretivist may access these meanings by observing and interacting with the actors whose actions they would like to explain, for example through extended and repeated interpretive interviewing (Fujii, 2018). Beyond simply interviewing actors about why and how they did what they did, researcher's can also utilize more participatory ethnographic techniques (REF). In Every Twelve Seconds (2013), Timothy Pachirat works undercover at a slaughterhouse to learn more about the routinization of killing and how actors make sense of this through his own active 
participation. The more embedded the researcher becomes in the setting, the more exposed researcher become to the multiplicity of experience-near understandings rendering actors' sayings and doings meaningful/meaningless in setting. Besides securing access to setting and actors, the most significant challenge to making trustworthy interpretivist knowledge-claims about these is the researcher's will and ability to reflect on what he learned through his encounters with actors in setting. By reflecting on the interplay between researcher's prior experience-distant understandings of the actors in setting and experience-near understandings acquired from researcher's actual encounters with situated actors (aka positionality), the interpretivist researcher becomes gradually aware of the crucial difference between what we thought we knew about why and how specific actors acted in certain ways and what we now know after having been exposed to actors' life world. The abductive process of confronting prior experience-distant understandings with the experience-near insights learned from interactions with actors in their setting is key to interpretivist epistemology (Yanow and Schwartz-Shea 2012: 27-34; Schwartz-Shea 2015). 


\section{Social process tracing}

In this section, we unpack what social process tracing at both the theoretical and empirical levels, flagging the value-added of keeping a dual focus on both the more material/objective side of processes, and the social relational context and how it is experienced and understood by social actors. In particular, we show how trying to tap into both experience-distant and experience-near empirics to understand how the underlying social dimension shapes the capacities of social agents to engage in activities and that shape the effect these activities have on other social agents.

[THIS SECTION IS LACKING THE ANCHORING IN THE BROADER PHILOSOPHICAL /SOCIOLOGICAL LITERATURE - ARCHER ETC - WILL BE UNDERTAKEN IN NEXT VERSION]

Figure 1 presents a causal process theory in which both the physical and social dimensions of the process are conceptualized in abstract terms. The top half of figure 1 is similar to process theory models found both in the natural and social sciences (e.g. Machamer et al, 2000; Machamer, 2000; Craver and Darden, 2013; Beach and Pedersen, 2019). While depicting a causal process as a causal graph involves black-boxing the crucial causal linkage role played by activities (e.g. Waldner, 2015), including the activities in the model enables the analyst to answer the 'how does it work' question (Craver and Darden, 2013; Piccinini, 2017). This is what can be thought of as the 'physical' dimension of a causal process, describing the 'moves' made by agents. The subsequent empirical analysis would attempt to figure out whether there is evidence of each part by assessing whether there are traces of the activities. However, we contend that this type of evidence is unable to help us unpack the social dimension of the process that provides the context within which the activities occur. We contend that learning about the social dimension enables the analyst to understand what 'game' the agents in the process are actually playing, what the 'rules' are, and how it can potentially change during the process. Without understanding how the social dimension creates capacities for action, we are left with a curiously experience-distant analysis that is missing the 'social'. 


\section{The physical dimension}

What moves do agents make in the 'game'?

(experience-distant)
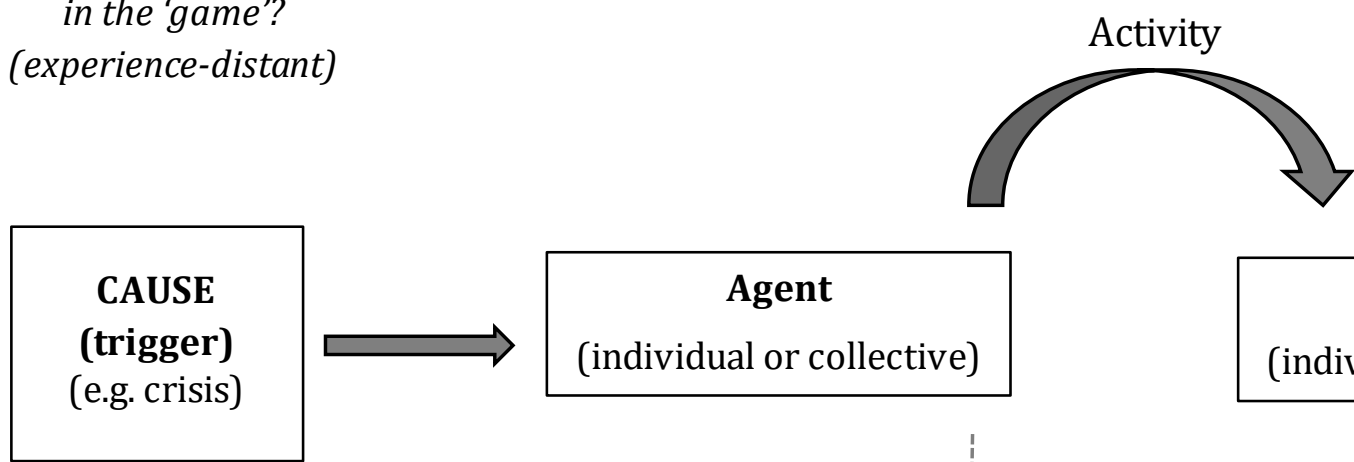

$$
\begin{gathered}
\text { Agent } \\
\text { (individual or collective) }
\end{gathered}
$$
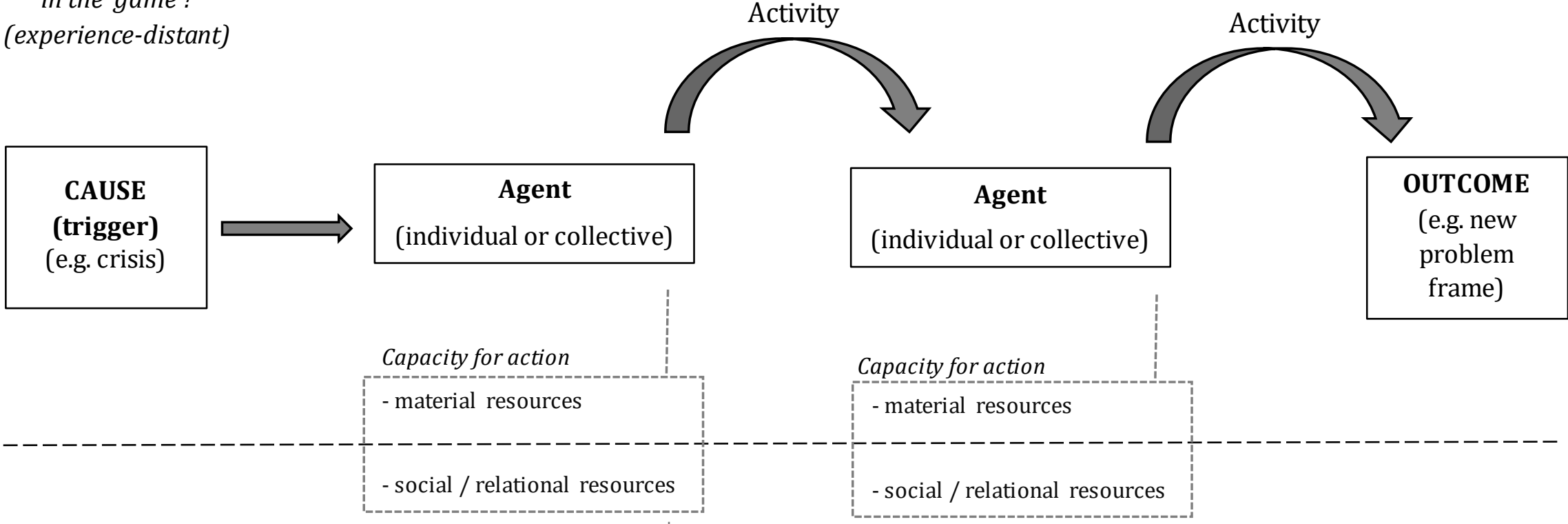

\section{The socialdimension}

What 'game'are the agents playing, whatare the rules, and how does it change over time?

(experience-near)

OUTCOME

(e.g. new problem frame)

Figure 1 - An abstract social process theory. 
In the philosophy of science, the language of entities engaging in activities is widely used when discussing how to unpack mechanistic explanations into their constituent parts (Machamer, Craver and Darden, 2000; Machamer, 2004; Illari and Russo, 2014). In the social sciences, entities can be micro-level (i.e. individuals) or macro-level (i.e. collective social actors), with the requirement being that the later have properties and orientations that enable them to do things that can impact other actors in a process. Micro-level social entities could be policy entrepreneurs or individual decision-makers, whereas macro-level entities might be epistemic communities or other forms of advocacy coalitions where the activities of the collective group cannot be reduced to the sum of individual actions (i.e. there is what sociologists term 'emergence').

Activities are what social entities do, and they are critical to mechanistic explanations. Activities might be things such as speech acts (speech or statements in conversations), using information to craft a new solution to a diagnosed problem by looking towards past cases (policy learning), or putting forward proposals in negotiations. When theorizing activities, it is also important to include some information about why the activity logically can be linked in a productive causal relationship with the social entity in the next part. For example, it is not enough to theorize that an entrepreneur engages in a speech act aimed at framing an issue that is followed by a policy-maker adopting the frame proposed. This does not tell us why the policy-maker would listen. In contrast, theorizing that the entrepreneur as a trusted epistemic authority puts forward a problem diagnosis that frames the issue sheds more light on why the speech act might influence the policy-maker, and it could then be empirically assessed in a case. This means that one should also think social dimension even during initial theorization.

The goal of social process tracing is to be able to develop an evidence-backed process theory of a given causal relationship. Figure 1 can therefore act as the template for the presentation of the theoretical findings of a social process tracing case study.

We now turn to methodological guidelines for engaging in social process tracing. Given that we propose using an explicitly abductive research process, we first discuss abduction and 
how it differs from widely-used theory-testing (deductive) and building (inductive) methods in process tracing. We then put forward key steps of social process tracing, noting of course that they are often iterated throughout the research process. We briefly review how 'normal' process tracing techniques for each step can be undertaken in parallel with more interpretive techniques for learning about the social dimension, and how the evidence can be merged.

The three steps are: 1) initial theorization using more experience-distant theoretical ideas to delimit what the process of interest is a 'case of' and how access can be obtained, 2) empirical probing to explore both experience-distant evidence of activities, but also probing the setting and gain more experience-near understandings of the process by observing and interacting with relevant actors and other forms of evidence (e.g. careful discourse analysis of documents), followed by a continuing dialogue between types of evidence in order to flesh out both dimensions of the studied causal process, moving back and forth between experience-distant knowledge and experience-near insights, and 3) assessing what is learned about the causal process and whether the theory can travel beyond the bounds of the studied case.

In developing the guidelines, we illustrate our suggestions for how a 'normal' process tracing can be supplemented with more experience-near evidence about the social dimension of the causal process using an article co-written by one of the authors that is under-review.

\section{Abductive research processes}

Social process tracing engages in abductive research practices in which there is a more-orless continuous back-and-forth between empirics and theoretical ideas to generate analytical abstractions about how social processes unfolded in real-world cases. In contrast, the typical account of process involves a theory-testing (more deductive) and theorybuilding (more inductive) approaches (e.g. Beach and Pedersen, 2019). Both deductive and inductive approaches follow a linear logic (that is the research progresses through a series of predetermined steps). Deduction outlines a theory, a rule or a hypothesis, tests it with empirical observation and either confirms or disconfirms it. A deductive approach thus 
deduces from the universal to the specific in order to produce testable hypotheses and then confronts these hypotheses with data. Induction starts with the collection of empirical observations and then infers or suggests a universal rule based on the empirical observations. Induction thus induces the universal from the specific (Peirce 1997, Tavory and Timmermans 2014, 4-5). Contrary to both deductive and inductive approaches, abductive reasoning is an iterative process that follows a circular or spiral pattern, moving back-and-forth between theory and empirical observations (Schwartz-Shea and Yanow $2012,26-34)$. Whereas deduction and induction from the beginning seek to either deduce from the universal or induce to the universal, abduction remains grounded in the specific (Schwartz-Shea and Yanow 2012,28). Researchers draw on other observations, studies, and scientific literatures from other settings but with the intention of making sense of what is happening in the specific setting or case.

Following a more abductive process allows the researcher to be flexible and open to surprising observations during the research process, for example pursuing interesting findings and adjusting the research to the empirical setting. This allows the researcher to be flexible and open to surprises during the research process that can lead to the reformulation of the theoretical question itself. Instead of selecting a 'case' on the basis of a priori theoretical considerations, 'casing' becomes an ongoing research activity in which the researcher seek to advance insight, understanding, and explanation by conceptualizing the particular in more abstract terms, as an instance bearing on something more general (Soss 2018). In social process tracing the temporal and spatial bounds of a case may thus shift during the research process. For example, when investigating how the actions of entrepreneurs (cause) construct a norm against the use of a particular weapon-type (outcome), we might encounter puzzling patterns in the rhetorical frames used by the enterpreneurs that could lead us to shift analytical focus onto the rhetorical framing and contestation processes themselves.

It is important to note that in an abductive research process, some of the evidence that is used in the final product to evidence our process theory is found in the initial empirical probing stages of research, whereas others might be found in the final, more theory-testing 
rounds. Scholars trained in a neo-positivist tradition might put forward two objections to this. First, neo-positivists would claim that evidence found in an initial probing ('context of discovery' to use Popper's term) cannot confirm a theory; it is only when found in a theorytest ('context of justification') that it can be admitted as evidence. However, what is critical in not when we found evidence in a research process, but whether we engage in a critical evaluation of what finding it means in relation to a theorized process, asking constantly whether there alternative explanations for finding the evidence.

Abduction is also a way of avoiding confirmation bias where the researcher finds confirmation of their prior-held theory by cherry-picking evidence. Abductive research processes avoid this through an interactive dialogue between theory and evidence, where the researcher constantly assesses found/not found evidence critically, asking whether there are alternative explanations. One of the alternative explanations for finding confirming evidence is always that it was cherry-picked and thereby does not reflect the broader empirical record. It is only when the analyst is able to substantiate that the confirming evidence is representative that it is then confirming. If there are more plausible alternatives, then the theory should be revised.

\section{3.c. Step 1 - initial theorization - developing a process theory sketch}

When researchers follow an abductive research process, they typically start with a puzzle, which is a surprising observation in relation to existing knowledge which they seek to explain (Schwartz-Shea and Yanow 2012, 28-30). This involves 'casing' (see above), where the researcher attempts to identify what might be the 'cause' and 'outcome' in relation to the

empirical phenomenon of interest by exploring theoretical debates and other forms of existing knowledge. Once this is done, the initial theorization can start with a theoretical brainstorm, inspired by existing theoretical ideas from relevant literatures.

This brainstorm should be informed by a wide-reaching survey of the literature. For example, if one is working with a theory of decision-making and negotiations in international 
negotiations, one can engage in a search in the literature on domestic policy-making and cognitive psychological literature on decision-making for inspiration about potential processes, or parts thereof. Using existing literature as inspiration, it can be helpful to write the cause (or set of causes) in one corner of a piece of paper, and the outcome in the other and then game through a plausible process linking them together. This can be thought of as a causal story, where the entities and activities are described for critical parts of the 'story'. Here it is important to consider both the 'physical' dimension of the process - as would be done in 'normal' process tracing, but some speculation should be made as regards the social context within which the process is hypothesized to be taking place.

The result is an initial process theory 'sketch', that contains very preliminary theoretical ideas that describe the critical parts of a causal process in terms of entities and activities, and that include some ideas about the social dimension.

As an example, in an under-review article co-written by one of the authors, we started with an empirical puzzle that we found difficult to explain: why EU leaders drew so heavily on lessons learned from the Irish collapse in October 2010 when diagnosing the causes of the Spanish banking crisis in spring 2012 even though the Spanish ills were quite different than the ones faced by Ireland. Having identified that we were interested in policy learning and problem diagnosis, the first step was to ask ourselves what we know from existing theorization. Given the explicit references to the Irish case in the subsequent policy discussions, the choice was made to focus on analogical reasoning as one form of policy learning related to problem diagnosis. However, existing research tended to black-box policy learning processes (Moyson etal, 2017: 166; Dunlop and Radaelli, 2017). This meant that we needed to develop an initial process theory sketch that could help us account for why smart policy-makers, backed by teams of policy experts, allowed themselves to be cognitively constrained by lessons learned from past cases about the causes of problems that might not be applicable in the case in hand.

Our initial process theory delineated the following steps (figure 2). While not published in the article, our initial theorization - based on existing literature and theoretical 
brainstorming - sketched several parts and the entities and activities hypothesized to be involved. Note that the critical part of the process, where learning takes place and the lessons learned from the past are then applied uncritically to the new crisis, remained more-or-less in a black-box at this point of the research (denoted by question marks).

What was not included in the original research, but what should be included in social process, is an explicit attempt to also uncover what the social 'game' being played was, along with the 'rules' of the game. This is included in figure 2, depicted as the social context that enables entities to have the capacity for particular actions.

\begin{tabular}{|c|c|c|c|c|c|}
\hline & Cause & \multicolumn{3}{|c|}{ Overlearning after policy failure process } & Outcome \\
\hline & Policy failure & $\begin{array}{l}\text { Experts assess } \\
\text { why failure } \\
\text { occurred }\end{array}$ & $\begin{array}{l}\text { ??? Some form } \\
\text { oflearning is } \\
\text { taking place } \\
\text { from failure } \\
\text { (storing } \\
\text { lesson) ??? }\end{array}$ & $\begin{array}{l}\text { Lesson learned } \\
\text { by experts from } \\
\text { past case is } \\
\text { applied by } \\
\text { policy-makers } \\
\text { to understand } \\
\text { new crisis }\end{array}$ & $\begin{array}{l}\text { Premature } \\
\text { consensus on } \\
\text { problem } \\
\text { diagnosis. }\end{array}$ \\
\hline 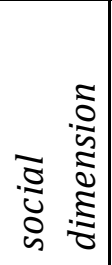 & & $\begin{array}{l}\text { game = experts } \\
\text { following } \\
\text { 'scientific' } \\
\text { procedures }\end{array}$ & $\begin{array}{l}\text { game = experts } \\
\text { following } \\
\text { 'scientific' } \\
\text { procedures }\end{array}$ & $\begin{array}{l}\text { epistemic } \\
\text { authority of } \\
\text { experts in } \\
\text { relation to } \\
\text { policy-makers }\end{array}$ & \\
\hline
\end{tabular}

Figure 2 - initial process theory sketch

\section{3.d. Step 2 -empirical probing and the dialogue between different types of evidence}

Once an initial process theory sketch is developed, the researcher can start empirical research, exploring whether: there is any evidence suggesting that the hypothesized parts took place, what was happening in parts of the process that are black-boxed, and enabling theoretical revision when parts of the initial sketch prove to be wrong. In this section, we discuss how empirical probing and theoretical revision is typically conducted in 'normal' 
process tracing, and how interpretivist techniques can be deployed in parallel in an attempt to unpack the social dimension.

\section{'Normal' process tracing}

After the initial sketch is developed, the researcher develops hypotheses about the potential observable manifestations an activity of an entity might leave in a given case, what can be termed mechanistic evidence (for more, see Beach and Pedersen, 2019). Here the researcher speculates about the evidence-generating process in the particular case, and what traces might be left by particular activities. This means that traces of activities can take many different empirical forms, ranging from the content of documents, accounts from participants, or statistics produced by public authorities. Given this, mechanistic evidence can be collected using a variety of research techniques, ranging from elite interviews to careful document analysis. As an example, in a process theory about policy diffusion, a part of the process might be that actors in country A seek inspiration for how to design a policy by looking at an adopted policy in country B. Potential traces of this activity could be that the subsequent policy in country A has a number of significant similarities with that in country $B$ that can act as a policy signature, or even that this policy signature includes elements that were developed to deal with the particular context in country B, but that do not really match the context in country A.

After initial hypotheses have been developed, we start exploring the empirical record to assess whether the predicted traces were actually present or not. If we find an observation, we have to ask ourselves whether the actual observation is really what we think it is and whether we can trust it. If we do not find an observation, we have to ask ourselves whether

we had access to the full empirical record or not. For example, if we are using participant interviews, our sources might have had incentives to hide events from us. If we do not have full access, we cannot conclude that absence of evidence is evidence of absence.

\section{Studying the 'social'}

'Normal' process tracing is blind to the underlying social dimension of causal processes. To shed more light on this requires the researcher adopt a more experience-near approach to 
gather and reveal the meanings that the participant in the study ascribe to their social reality. In short, it involves paying attention to the perspective of the people being studied. This can be achieved using a range of interpretive techniques, including ethnographic field research (e.g. Schatz, 2009), interpretive interviewing (e.g. Fujii, 2018), and discourse analysis (Fairclough, 2010). In the following we present initial ideas about how this can be done. It is also important to note that in practical research, it will be impossible for the researcher to do both a 'normal' process tracing case study and a rigorous interpretive analysis. This means that in reality, the researcher has to be pragmatic about how in depth they can go in both of the approaches. As regards the interpretivist side of the analysis, one way this can be done is by focusing analysis on asking questions about what 'game' agents are playing, what are the 'rules', and how they change over time. Here, even a relatively cursory set of interpretive interviews can shed more light on how the social dimension created capacities for action that enabled the causal process to play out as it did in a particular case.

How then can we study the social? We start by arguing that this entails adopting a particular 'mind-set', before moving on to proposing some methodological techniques that can be used to access and examine the meanings of participants. Finally, this section discuss some important aspects that researchers should be aware of when doing this kind of research, namely questions of positionality and reflexivity.

An ambition to bring in the social dimension in the causal explanation requires the researcher pays attention to the perspectives of the participants in the case, and how they for instance understand the social 'game' they are playing. To reveal the meanings these people attribute to a process, an interaction, a piece of legislation etc. It may seem as if this is something which can rather quickly be done by conducting a series of 'semi-structured' interviews or deploying a survey. However, we argue that this is not merely a question of gathering information. It is also an epistemological commitment to '...care to glean the meanings that the people under study attribute to their social and political reality' (Schatz, 2009:5), which transcends the distinction between data generation and analysis. Fujii writes that, '...meaning and action are so closely intertwined that it would be impossible to explain 
differences in behavior without taking into account differences in how people make sense of the situations they face.' (2018: 75).

In other words, it is notjust aboutgetting information, but it is also accessing meaning, which requires what ethnographers sometimes refer to as an 'ethnographic sensibility' (Pader, 2014). Ethnographic sensibility involves combining an awareness of details (e.g. which words did the actor use when he criticized the bill? How was the tone of his voice?) with an orientation towards the meanings of these details in the particular social context (e.g. was he being dismissive or seeking to compromise?). In order to uncover the meaning of details in the particular context it is fruitful for the researcher to immerse herself in the research setting. There are several ways to do so, and which one to choose is a matter of the particularities of the research project. In the following, we briefly outline two approaches that we believe could be productive when conducting social process tracing - fieldwork and interpretive interviewing. The techniques described in this section for the most part presuppose that the process the scholars is interested in is on-going. However, researchers engaging in social process tracing will often be occupied with a completed process (the relation between a cause and an outcome). Fieldwork can still be a beneficial approach in order to learn about the case and the social context. For example, spending six months embedded in a particular bureaucratic organization can help the researcher afterwards understand things such as what actors might mean when they make particular statements.

\section{Fieldwork: being there, observing and experiencing}

Doing more interpretive-inspired fieldwork can be a way of immersing yourself in the setting that you are studying. Interpretive fieldwork differs from many other methods used in social science since the researcher is not constructing and managing the research situation. Instead, the researcher becomes a part of an existing site and has to establish a relationship with the members of the field because this relationship is not structured by the research situation as it would be if the researcher were conducting interviews (Bernard 2011). Doing fieldwork thus entails entering an empirical site (the field) that pre-exists the research

situation, becoming a member (of some kind) of the field and establishing a relationship with the members of this field (Gans 1968, 63-96, Hammersley and Atkinson 2007). Doing 
fieldwork thus also involves the researcher subjecting herself to the situation of the people she is studying (Goffman 1989). In other words, fieldwork in ethnographic research entails that the researcher observes what the people in the field do as well as the researcher experiencing for herself how it is to be part of the social situations in the field (Goffman 1989, Emerson, Fretz et al. 2011, 2-5).

There are different forms of doing fieldwork (of observing and experiencing the field). Participant observation is a common method for generating data in fieldwork, which involves taking part in all or some activities in the social setting she is studying while also observing and taking notes (Gold 1958, Spradley 2016). Participant observation involves immersing yourself in the culture of your setting and learning to remove yourself every day from that immersion so you can intellectualize what you have seen or heard. Participant observation turns fieldworkers into instruments of data generation and data analysis (Bernard 2011). During fieldwork, the researcher studies an object in its natural environment, but the presence of the researcher will inevitably spoil the naturalness of the site (Bernard 2011). In most cases, it will provoke reactions by the members of the field, but as they get used to the researcher, their reactivity decreases (ibid.). That is why ethnographers have traditionally stressed the point of 'going to the field and staying there', which means spending a considerable amount of time in the field - exposing yourself to the field. For a scholar doing social process tracing, participant observation can contribute to understanding an ongoing process by making it possible for the researcher to actually observe what is going on while it is going on; what are the actors doing, who are they talking to about what, where are they going etc. In other words, it becomes possible to observe the "moves of the game" - the interactions between actors in the setting. Participant observation makes it possible to study actions as they unfold instead of inferring what happened from people's accounts (Jerolmack and Khan, 2014). Participant observation is also a way of learning about the culture in the setting - a way to learn and experience the implicit knowledge and norms in the field (for example the informal procedures surrounding the passing of a bill in a parliament). 
Participant observation is not the only type of fieldwork that could be relevant for scholars doing social process tracing. Shadowing is another technique for generating data in fieldwork and involves a researcher closely following a (or multiple) member(s) of an organization over an extended period of time (Czarniawska: 2007). What sets shadowing apart from participant observation is the focus on a single or multiple roles of organizational actors. The researcher thus obtains insight into a focused and specific experience which is relevant to a particular expert role. This could be relevant in cases where particular entities or actors are central to the causal explanation. Inspired by the genre multi-sited or multilocal ethnography (Hannerz, 2003), the researcher can also shadow an artefact for example a law proposal. Instead of following an organizational actor around in his or her work life, the researcher would follow for example the document throughout the process.

Doing fieldwork will almost inevitably involve asking some form of questions to participants. First because talking is a part of interacting and participating in a social setting, and second because can be difficult to grasp the imagined meaning of the participants without asking questions (Lamont and Swidler 2014). Emotional dimensions of social experiences are not necessarily evident in behavior, and it may be necessary to make the participants reflect upon their perceptions and understandings. In order to do this, the researcher must ask questions, using techniques such as interpretive interviewing (ibid; Fujii, 2018).

Conducting interpretive interviews with participants has benefits because it enables systematic comparison across individuals, groups and social settings (ibid). There are various techniques for conducting interviews, and which approach to adopt is a question of the specific research project, the case, the process and the research question. However, for studying "the social" (for gleaning the meanings of participants) it is important not to consider your interview participants as "informants" - knowledgeable actors who provides the researcher with information about what happened (Weiss, 1994). Instead, interview participants should be approached as "representatives" - as individuals whose lifeworld the researcher wishes to access. In other words, the aim of these interviews is to gain an understanding of why actors acted in the way they did and how actors perceive specific actions. From such interviews, the scholar might learn that seemingly important actions 
were not intentional or unfolded quite differently from what some actors thought they would, because they were not aware of social and material resources used.

An interview technique that can be fruitful is narrative interviewing. Since many scholars doing process tracing are tracing processes that have already occurred (they are interested in the relation between a cause and an outcome which is in the past), conducting narrative interviews is a way of getting participants to tell the story of the process from their point of view. Narrative interviewing is a method of qualitative data collection whereby a story is generated through the interview. The purpose of narrative interviews is to provide an opportunity for the participant to narrate his or her experience for the researcher. It will always be a narrative about the past told from the present (Czarniawska, 2004). However, narrative interviewing is also a way to "ground meaning-making in practice" by encouraging interview participants to tell their story about concrete events (Maynard-Moody and Musheno, 2006).

\section{The importance of positionality}

Being exposed to the social setting of the process, scholars often stumble on puzzling actions that need to be explained, unexpectedly encounter actors that need to be included or that material and social resources the scholar considered valuable are perceived as useless by the actors. As a consequence, the most frequentoutcome is alteration of the theorization and research design (see also Fujii 2015). However, to realize that one's theory and design need changes after being with actors in the setting, the researcher must be aware of how his positionality influences the degree of access and interpretations of what have been observed and interactions in the setting. By positionality we mean the demographic, locational as well as theoretical "position" of the researcher in the research setting. Demographic positionality refers to the visible (e.g., gender, race, and clothing) and invisible traits (e.g., religious and political convictions, socio-economic background, and sexuality) of the researcher. Locational positionality refers the physical location of the researcher in the field and how this positions influence what the researcher can observe and access, while theoretical positionality concerns how the theoretical and analytical lens (the experience distant concepts) that the researcher inevitably brings to the field influence what she sees. Being 
aware of how these forms of positionality influence access and interpretations of the encounters with actors in settings, these may be used actively and strategically to enhance embeddedness and further ground one's knowledge-claims in context (Reyes 2020: 224).

\section{Combining experience-distant and experience-near evidence}

Social process tracing involves the explicit attempt to draw on both experience-distant and experience-near evidence in order to revise the process theory as it played out in a given case. How then can they be merged?

The shortanswer is that they should be deployed in an abductive, iterated dialogue using the questions developed in figure 1. For example, through repeated empirical probing we might have been able to flesh out an activity that an entity is engaging in that we think is the crucial causal link to the next part of the process. This should then spur the researcher to ask about the social dimension of this activity. What was the social 'game' being played when the entity engaged in the activity? This can only be understood through more interpretive techniques, for example asking participants about their understandings of the game being played.

Returning to the previously discussed case study, the 'normal' process tracing uncovered a sequence of events in which an initial expert study that detailed the causes of the Irish economic collapse in October 2010, followed by a think-tank expert translating these contextualized lessons into an abstract lesson (a 'vicious circle' problem) that could potentially apply to many other cases, a lesson that quickly came to dominate the economic debate amongst experts both within the EU bureaucracy and in outside think tanks like Bruegel. What was particularly puzzling for us was how this abstract lessons diffused so quickly amongst these experts. In order to understand this, we did use more interpretive interviewing techniques to try to uncover the meanings behind the actions of actors like the think tank expert. In our interviews, we probed how actors understood the social context, asking them about their everyday practices - e.g. who they met with and what types of interactions they engaged in. We listened very carefully to what actors were telling us, noticing the types of words used and inquiring about them. Through these interviews, our informants helped us understand the epistemic community within which these different 
actors were embedded, and what the rules of the social game being played within this community. We found out that while there were formal institutional barriers, in practice there was a small informal network of economic experts from the EU institutions (European Commission and the European Central Bank), the International Monetary Fund, and the Bruegel think tank that engaged in close dialogue on the banking/sovereign issue. We could then use this information to qualify our understanding of why particular activities such as the publication by a single think tank expert of an abstract lesson could resonate so strongly within this community.

If we had implemented social process tracing methods fully, we would have spenteven more time probing how this 'game' between experts, and the ensuing game between experts and high-level national civil servants (sherpas) and politicians worked. We would of course not want to lose sight of the more physical dimension of activities, also attempting to map networks of communication, and trying to figure out what types of meetings were held when, and with what results.

\section{3.e. Step 3 - Do we learn anything more generally?}

A typical question asked by critical reviewers of a careful process tracing case study is whether the process theory works in other cases; in other words, can we generalize from the particular to other cases? If so, what is the relevant population to which we can generalize? Given that doing a normal process tracing case study is very analytical taxing, providing an evidence-backed answer to this question is nearly impossible.

When speaking of social process tracing, this question becomes even more challenging because the knowledge-claims would be so closely bound to the social context in the particular case. However, while unpacking causal processes into their constituent parts is crucial, the resulting process theory can have differing levels of theoretical abstraction, depending on our research goals. Mechanistic explanations can range from relatively abstract process models that can be seen as mechanistic sketches where the resulting process 
theory can be present in many different cases - to very detailed, case-specific mechanistic explanations in which entities are described using formal nouns (e.g. particular persons) and where the historical intricacies of the particular process in a case are unpacked in considerable detail. 
4. Conclusions

[TO BE WRITTEN] 


\section{References}

Archer (1995)

Beach, Derek and Jonas Gejl Kaas. 2020. The Great Divides: Incommensurability, the Impossibility of Mixed-Methodology and What to Do about It., International Studies Review, doi: 10.1093/isr/viaa016

Beach, Derek and Rasmus Brun Pedersen.2019. Process-tracing - foundations and guidelines. 2nd Edition. Ann Arbor: University of Michigan Press.

Bennett, Andrew and Jeffrey Checkel. Eds. 2014. Process Tracing: From Metaphor to Analytical Tool. Cambridge: Cambridge University Press.

Bernard H. R. (2011). Research methods in anthropology : qualitative and quantitative approaches. Lanham, Md., AltaMira Press: 666

Bevir, Mark and Jason Blakely. 2018. Interpretive Social Science: An Anti-Naturalist Approach. Oxford: Oxford University Press.

Bhaskar, Roy. 1978. A Realist Theory of Science. Brighton: Harvester.

Bourdieu, Pierre and L.J.D. Wacquant. 1996. An Invitation to Reflexive Sociology. Chicago: University Of Chicago Press.

Collier, David, Henry E. Brady and Jason Seawright. 2010. Sources of Leverage in Causal Inference. in Brady, Henry E., and David Collier, eds. Rethinking Social Inquiry: Diverse Tools Shared Standards. 2nd ed. Lanham MD: Rowman Littlefield, pp. 161-200.

Clarke, B., D. Gillies, Phyllis Illari, Federica Russo, Jon Williamson. 2014. Mechanisms and the Evidence Hierarchy. Topoi, 33(2): 339-360. 
Craver, Carl F. and Lindley Darden. 2013. In Search of Mechanisms: Chicago: University of Chicago Press.

Czarniawska, B. (2007). Shadowing, and other techniques for doing fieldwork in modern societies. Malmø: Liber.

Czarniawska, B. 2004. Narratives in an interview situation., in Czarniawska, B. Narratives in social science research. Introducing qualitative methods. London: Sage Publications, pp. 5060.

Danermark, Berth, Mats Ekström and Jan Ch. Karlsson. 2019. Explaining Society. Critical Realism in the Social Sciences. Second Edition. London: Routledge.

Emerson, R. M., Fretz, R. I., \& Shaw, L. L. (2011). Writing ethnographic fieldnotes (2. edition ed.). Chicago: The University of Chicago Press.

Fairfield, Tasha and Charman, Andrew. 2019. A Dialogue with the Data: the Bayesian foundations of iterative research in qualitative social science. Perspectives on Politics, 17(1): 154-167.

Fairclough, Norman. 2010. Critical Discourse Analysis: The Critical Study of Language. Second Edition. London: Routledge.

Falleti, Tulia G. and Julia F. Lynch. 2009. Context and Causal Mechanisms in Political Analysis. Comparative Political Studies 42:1143-1166.

Fujii, Lee ann. 2015. Five stories of accidental ethnography: turning unplanned moments in the field into data. Qualitative Research, 15(4): 525-539. 
Fujii, Lee Ann. 2018. Interviewing in Social Science Research: A Relational Approach. London: Routledge.

Gans, H. J. (1968). The participant observer as a human being: Observations and the personal aspects of fieldwork. Institutions and the person: Festschrift in honor of Everett C. Hughes. H. G. Becker, Blanche \& Weiss, Roberts S \& Riesman, David. Chicago, Aldine

Geertz, C.. 1974. "From the Native's Point of View": On the Nature of Anthropological Understanding. Bulletin of the American Academy of Arts and Sciences, 28 (1): 26-45.

Goffman, E. (1989). "On Fieldwork." Journal of Contemporary Ethnography 18(2): 123-132.

Gold, R. L. (1958). "Roles in Sociological Field Observations." Social Forces 36(3): 217-223

Hammersley, M. and P. Atkinson (2007). Ethnography : principles in practice. London, Routledge.

Hannerz, U.. 2003. Being there... and there...and there!: Reflections on Multi-Site Ethnography. Ethnography, 4(2): 201-216. doi:10.1177/14661381030042003

Illari, Phyllis McKay. 2011. Mechanistic Evidence: Disambiguating the Russo-Williamson Thesis. International Studies in the Philosophy of Science 25 (2): 139-57.

Illari, Phyllis McKay and Federica Russo. 2014. Causality: Philosophical Theory meets Scientific Practice. Oxford: Oxford University Press.

Jackson, Patrick Thaddeus. 2006. Civilizing the Enemy: German Reconstruction and the Invention of the West. Ann Arbor: University of Michigan Press.

Jackson, Patrick Thaddeus. 2016. The Conduct of Inquiry in International Relations: Philosophy of Science and Its Implications for the Study of World Politics. New York: Routledge. 
Jerolmack, C., \& Khan, S.. 2014. Talk Is Cheap : Ethnography and the Attitudinal Fallacy. Sociological Methods \& Research, 43(2): 178-209. doi:10.1177/0049124114523396

Machamer, Peter. 2004. Activities and Causation: The Metaphysics and Epistemology of Mechanisms. International Studies in the Philosophy of Science 18 (1): 27-39.

Machamer, Peter, Lindley Darden, and Carl F. Craver. 2000. Thinking about Mechanisms. Philosophy of Science 67 (1): 1-25.

Malinowski, B. (1922). Agronauts of the Western Pacific. London, Routledge.

Maxwell, Joseph A.. 2012. A Realist Approach for Qualitative Research. London: Sage Publications.

Maynard-Moody, Steven \& Michael Musheno. 2006. Stories for Research. In Dvora Yanow and Peregrine Schwartz-Shea, Interpretation and Method. Empirical Research Methods and the Interpretive Turn, Armonk: M. E. Sharpe, pp. 316-330.

Pachirat, Timothy. 2013. Every Twelve Seconds. New Haven: Yale University Press.

Pader, E.. 2014. Seing with an Ethnographc Sensibility. In Dvora Yanow and Peregrine Schwartz-Shea. Eds, Interpretation and Method: Empirical Research and the Interpretive Turn. N.Y.: M.E. Sharp, Inc, pp. 194-208

Piccinini, Gualtiero. 2017. Activities Are Manifestations of Causal Powers. in M.P. Adams, Z. Biener, U. Feest and J. A. Sullivan (eds) Eppur si muove: Doing History and Philosophy of Science with Peter Machamer. Cham, Switzerland: Springer, pp. 171-182. 
Pouliot, Vincent. 2014. Practice Tracing. in Bennett, Andrew and Jeffrey Checkel. Eds. 2014. Process Tracing: From Metaphor to Analytical Tool. Cambridge: Cambridge University Press, pp. ???.

Reyes, V.. 2020. Ethnographic toolkit: Strategic positionality and researchers' visible and invisible tools in field research. Ethnography, 21(2): 220-240.

Sawyer, R. Keith. 2005. Social Emergence. Societies as Complex Systems. Cambridge: Cambridge University Press.

Sayer, Andrew. 2000. Realism and Social Science. London: Sage Publishing.

Schaffer, Fred. 2012. Thin Descriptions: The Limits of Survey Research on the Meaning of Democracy. Polity, 46(3): 303-330.

Schaffer, Fred. 2016. Elucidating Social Science Concepts. New York: Routledge.

Schatz, Edward. 2009. Political ethnography : what immersion contributes to the study of power. Chicago: University of Chicago Press.

Schwartz-Shea, Peregrine. 2015. Interpretive Social Science, in Gibbons, M. T. et al. (eds) The Encyclopedia of Political Thought. Hoboken: John Wiley \& Sons, pp. ???

Sewell, William H.. 1992. A Theory of Structure: Duality, Agency, and Transformation. American Journal of Sociology, 98 (1): 1-29.

Sewell, W.H.. 1996. Historical Events as Transformations of Structures: Inventing Revolution at the Bastille. Theory and Society, 25(6): 841-881.

Somers, M. R., \& Block, F. 2005. From Poverty to Perversity: Ideas, Markets, and Institutions over 200 Years of Welfare Debate. American Sociological Review, 70(2); 260-287. 
Spradley, J. P. (2016). Participant observation. Long Grove, IL, Waveland Press.

Tavory, I. and Timmermans, S.. 2014. Abductive Analysis: Theorizing Qualitative Research. Chicago: University of Chicago Press.

Weiss, Robert S.. 1994. Learning from Strangers. The Art and Method of Qualitative Interview Studies. New York: The Free Press.

Yanow, Dvora and Peri Schwartz-Shea. 2014. Interpretation and Method. New York: Routledge.

Yanow, Dvora and Peri Schwartz-Shea. 2012. Interpretive Research Design. New York: Routledge. 